\title{
Peptoid Library Agar Diffusion (PLAD) Assay for the High-Throughput Identification of Antimicrobial Peptoids
}

Kevin J. Fisher, Jeremy A. Turkett, Ashley E. Corson, Kevin L. Bicker

Middle Tennessee State University, Department of Chemistry, 1301 E. Main St., Murfreesboro, TN 37132.

\section{Table of Contents}

I. Synthesis and Screening Procedures...................S2-S15

II. Supporting Figures...............................S16-S30

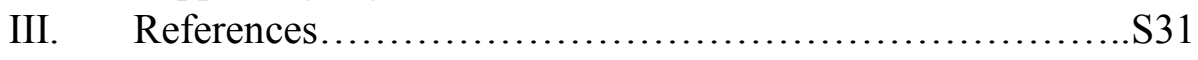




\section{Synthesis and Screening Procedures}

\section{Materials and Methods}

Chemicals for this project were purchased from Fisher Scientific (Waltham, MA), Alfa Aesar (Haverhill, MA), Amresco (Solon, OH), TCI America (Portland, OR), Anaspec (Fremont, CA), EMD Millipore (Billerica, MA), Peptides International (Louisville, KY), and Chem-Implex (Wood Dale, IL). Non-pathogenic E. coli (ATCC 25290) were provided by Dr. Mary Farone in the Department of Biology at Middle Tennessee State University (MTSU). All mass spectra were acquired on either a Waters Synapt HDMS QToF with Ion Mobility or a Thermo Scientific LTQ XL Linear Ion Trap Mass Spectrometer and all NMR spectra were acquired on a JOEL ECA 500 NMR spectrometer. All images were acquired using a Leica M165FC stereomicroscope and images were analyzed using Adobe Photoshop and Microsoft Excel.

\section{$N$-(tert-butoxycarbonyl)-cystamine}

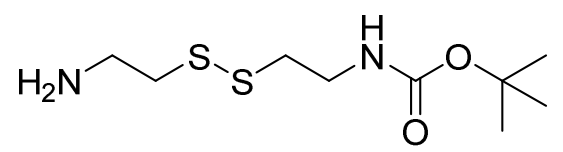

Cystamine dihydrochloride (4 g, $17.78 \mathrm{mmol})$ was dissolved in methanol (200 mL) and cooled to $0^{\circ} \mathrm{C}$. Triethylamine $(7.45 \mathrm{~mL}, 53.33 \mathrm{mmol})$ was added and stirred for $30 \mathrm{~min}$. Bocanhydride (4.05 mL, $17.78 \mathrm{mmol})$ was then added drop wise over $10 \mathrm{~min}$ and allowed to stir for $1 \mathrm{~h}$. The solution was concentrated in vacuo, then washed with diethyl ether $(3 \mathrm{x} 30 \mathrm{~mL}) .1 \mathrm{M}$ $\mathrm{NaOH}$ solution was added to the product and extracted $2 \mathrm{x}$ with $\mathrm{CH}_{2} \mathrm{Cl}_{2}$. Both organic layers were combined and washed $2 \mathrm{x}$ with $\mathrm{H}_{2} \mathrm{O}$. The organic layer was then dried over $\mathrm{CaCl}_{2}$ and concentrated in vacuo to yield a white solid (3.9 g, 86\% yield). ESI $[\mathrm{M}+\mathrm{H}]^{+1}$ expected 253.39 
Da, observed 253.1 Da. ${ }^{1} \mathrm{H}$ NMR $\left(\mathrm{CDCl}_{3}\right) \delta 1.45(\mathrm{~s}, 9 \mathrm{H}), \delta 2.77(\mathrm{q}, 4 \mathrm{H}, \mathrm{J}=6.19 \mathrm{~Hz}), \delta 3.02(\mathrm{t}$, $4 \mathrm{H}, \mathrm{J}=6.19 \mathrm{~Hz}), \delta 3.45(\mathrm{~m}, 2 \mathrm{H}), \delta 5.02(\mathrm{~s}, 1 \mathrm{H})$.

$N$-(tert-butoxycarbonyl)-1,4-diaminobutane

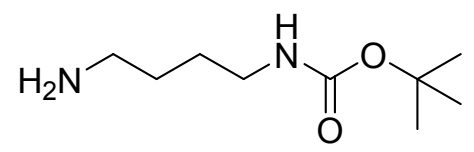

Concentrated $\mathrm{HCl}(2.85 \mathrm{~mL}, 34.09 \mathrm{mmol})$ was added to methanol $(50 \mathrm{~mL})$ and cooled to $0^{\circ} \mathrm{C}$ on ice. 1,4-Diaminobutane ( $\left.3 \mathrm{~g}, 34.09 \mathrm{mmol}\right)$ was added to the mixture and stirred for 20 min. Water $\left(\mathrm{ddH}_{2} 0 ; 7 \mathrm{~mL}\right)$ was added and stirred 30 minutes. Di-tert-butyl dicarbonate $(11.72$ $\mathrm{mL}, 51.11 \mathrm{mmol})$ in methanol $(30 \mathrm{~mL})$ was added drop wise over $10 \mathrm{~min}$ then stirred for $1 \mathrm{~h}$. The solvent was evaporated in vacuo and the resulting solid washed with diethyl ether (3x 30 mL). $1 \mathrm{M} \mathrm{NaOH}$ solution was added and the product was extracted $2 \mathrm{x}$ with $\mathrm{CH}_{2} \mathrm{Cl}_{2}$. Both organic layers were combined and washed $1 \mathrm{x}$ with a brine solution. The organic layer was then dried over $\mathrm{CaCl}_{2}$ and concentrated in vacuo to yield a white solid (4.81 g, 75\% yield). ESI $[\mathrm{M}+\mathrm{H}]^{+1}$ expected 189.27 Da, observed 189.2 Da. ${ }^{1} \mathrm{H}$ NMR (500 MHz, $\left.\mathrm{CDCl}_{3}\right): \delta 4.61(\mathrm{~s}, 1 \mathrm{H})$, $3.13(\mathrm{~m}, 2 \mathrm{H}), 2.17(\mathrm{~m}, 2 \mathrm{H}), 1.50(\mathrm{~m}, 6 \mathrm{H}), 1.44(\mathrm{~s}, 9 \mathrm{H})$. 


\section{$N$-(tert-butoxycarbonyl)-1,2-diaminoethane}

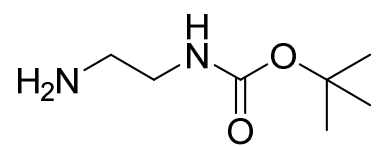

Concentrated $\mathrm{HCl}(3.89 \mathrm{~mL}, 46.6 \mathrm{mmol})$ was added to methanol $(50 \mathrm{~mL})$ and cooled to $0^{\circ} \mathrm{C}$ on ice. 1,2-Diaminoethane $(2.8 \mathrm{~g}, 46.6 \mathrm{mmol})$ was added to the mixture and stirred for 20 min. Water $\left(\mathrm{ddH}_{2} 0 ; 8 \mathrm{~mL}\right)$ was added and stirred 30 minutes. Di-tert-butyl dicarbonate (16.08 $\mathrm{mL}, 70.0 \mathrm{mmol})$ in methanol $(34 \mathrm{~mL})$ was added drop wise over $10 \mathrm{~min}$ then stirred for $1 \mathrm{~h}$. The solvent was evaporated in vacuo and the resulting solid washed with diethyl ether (3x $30 \mathrm{~mL}) .1$ $\mathrm{M} \mathrm{NaOH}$ solution was added and the product was extracted $2 \mathrm{x}$ with $\mathrm{CH}_{2} \mathrm{Cl}_{2}$. Both organic layers were combined and washed $1 \mathrm{x}$ with brine. The organic layer was then dried over $\mathrm{CaCl}_{2}$ and concentrated in vacuo to yield a white solid (2.92 g, 39.2\% yield). ESI [M+H] $]^{+1}$ expected 161.22 Da, observed 161.1 Da. ${ }^{1} \mathrm{H}$ NMR (500 MHz, $\mathrm{CDCl}_{3}$ ): $\delta 4.85$ (s, 1H), $3.09(\mathrm{~m}, 2 \mathrm{H}), 2.67$ (q, 2H, $\mathrm{J}=6.30 \mathrm{~Hz}), 1.46(\mathrm{~m}, 2 \mathrm{H}), 1.43(\mathrm{~s}, 9 \mathrm{H})$.

\section{Branched Disulfide Linker Synthesis}

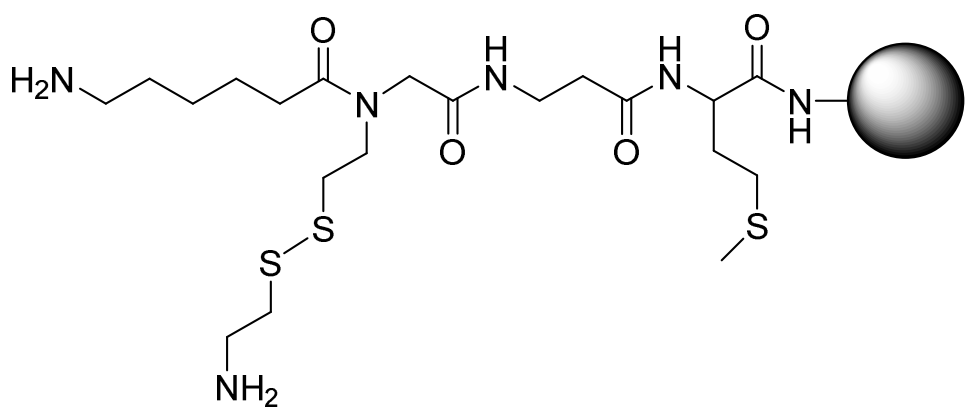

$500 \mathrm{mg}$ of TentaGel macrobeads $(0.25 \mathrm{mmol} / \mathrm{g}$ loading capacity) were swollen for $20 \mathrm{~min}$ in dimethylformamide (DMF). Fmoc-Met-OH (320 mg, $0.82 \mathrm{mmol}, 7$ eq.) was activated with 
$N, N, N^{\prime}, N^{\prime}$-tetramethyl-O-(1H-benzotriazol-1-yl)uronium hexafluorophosphate (HBTU; $330 \mathrm{mg}$, $0.82 \mathrm{mmol}$, 7eq.) for $10 \mathrm{~min}$ in $10 \mathrm{~mL}$ DMF with $5 \% \mathrm{~N}$-methylmorpholine (NMM; v/v). This solution was then added to the TentaGel resin and allowed to react for $1 \mathrm{~h}$ with gentle rocking. Fmoc deprotection of the methionine was accomplished using $10 \mathrm{~mL}$ of $20 \%$ piperidine/DMF (v/v) solution for $10 \mathrm{~min}$ twice. Fmoc- $\beta$-Ala-OH $(270 \mathrm{mg}, 0.87 \mathrm{mmol}, 7$ eq.) was activated with HBTU (330 mg, $0.87 \mathrm{mmol}, 7$ eq.) for $10 \mathrm{~min}$ in $10 \mathrm{~mL}$ DMF with 5\% NMM (v/v), added to the resin and allowed to react for $1 \mathrm{~h}$ with gentle rocking. Fmoc deprotection was again

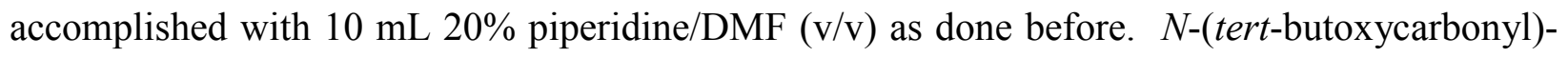
cystamine was next incorporated using peptoid submonomer synthesis. ${ }^{1}$ Briefly, bromoacetic acid (1.38 g; $10 \mathrm{mmol})$ in anhydrous DMF $(5 \mathrm{~mL})$ was mixed with diisopropylcarbodiimide (DIC; $2.5 \mathrm{~mL} ; 16 \mathrm{mmol})$ in anhydrous DMF $(5 \mathrm{~mL})$ and added to the resin. The reaction was then microwaved in a $1000 \mathrm{~kW}$ commercial microwave at $10 \%$ power $(100 \mathrm{~kW})$ for $15 \mathrm{~s}$ twice and rocked gently for $15 \mathrm{~min} . \quad N$-(tert-butoxycarbonyl)-cystamine (550mg, $2.2 \mathrm{mmol}, 17 \mathrm{eq}$.) was added to the resin in $8 \mathrm{~mL}$ anhydrous DMF, microwaved at $10 \%$ power for 15 seconds twice and rocked gently for $45 \mathrm{~min}$. Fmoc-6-aminohexanoic acid (Fmoc-Aca-OH; 175mg, $0.50 \mathrm{mmol}$, 4 eq.) was activated with $\mathrm{HBTU}$ ( $187 \mathrm{mg}, 0.50 \mathrm{mmol}, 4$ eq.) for $10 \mathrm{~min}$ in $10 \mathrm{~mL} \mathrm{DMF}$, added to the resin, and allowed to react for $1 \mathrm{~h}$ with gentle rocking. Boc group deprotection from the cystamine side chain was then done using $10 \mathrm{~mL}$ of a $95 \%$ TFA/2.5\% $\mathrm{H}_{2} \mathrm{O} / 2.5 \%$ triisopropylsilane (TIS) mixture for $1 \mathrm{~h}$ followed by washing $5 \mathrm{x}$ with $\mathrm{CH}_{2} \mathrm{Cl}_{2}$ and $5 \mathrm{x}$ with DMF. Deprotection of the remaining Fmoc group was done with 20\% piperidine/DMF (v/v) followed by washing $4 \mathrm{x}$ with DMF. All reactions were tested with a ninhydrin color test, and after each reaction the resin was washed $4 \mathrm{x}$ with DMF unless stated otherwise. 


\section{Synthesis of PLAD Linked Test Peptoid}

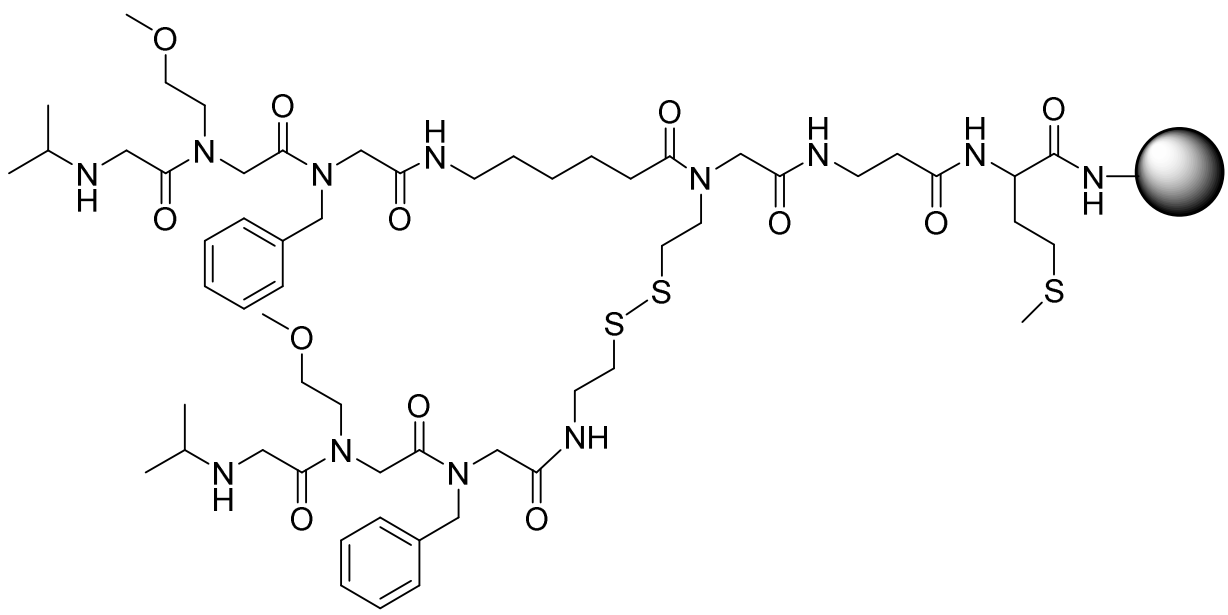

Solutions of bromoacetic acid $(0.417 \mathrm{~g} ; 3 \mathrm{mmol})$ in anhydrous DMF $(1.5 \mathrm{~mL})$ and DIC $(0.75 \mathrm{~mL} ; 4.8 \mathrm{mmol})$ in anhydrous DMF $(1.5 \mathrm{~mL})$ were combined with $50 \mathrm{mg}$ of resin immobilized PLAD linker. The suspended resin was microwaved twice at 10\% power (100 kW) for 15 seconds, then rocked gently for 15 minutes. After the prescribed time, the mixture was aspirated and washed four times with DMF. Benzylamine $(0.643 \mathrm{~g} ; 6 \mathrm{mmol})$ in anhydrous DMF $(3.0 \mathrm{~mL})$ was added to the resin and microwaved twice at $10 \%$ power for 15 seconds followed by gentle rocking for 15 minutes. The suspension was aspirated and washed $4 \mathrm{x}$ with DMF. The previously described bromoacetic acid and DIC reaction was repeated. 2-methoxyethylamine (0.451 g; $6 \mathrm{mmol})$ in anhydrous DMF $(3.0 \mathrm{~mL})$ was added, microwaved, and rocked for 15 minutes. The suspension was then aspirated and washed 4x with DMF. Again, the bromoacetic acid and DIC coupling was repeated. Isopropylamine $(0.355 \mathrm{~g} ; 6 \mathrm{mmol})$ in anhydrous DMF (3.0 $\mathrm{mL}$ ) was added to the resin, microwaved, and rocked for 15 minutes. The mixture was aspirated and washed $4 \mathrm{x}$ with DMF. All reactions were tested using a ninhydrin color test.

The complete test peptoid was analyzed by treating a small aliquot of resin with $75 \mu \mathrm{L}$ of cyanogen bromide $(\mathrm{CNBr} ; 40 \mathrm{mg} / \mathrm{mL}$ ) in 80:20 acetonitrile (ACN): water containing $0.1 \mathrm{M} \mathrm{HCl}$ 
for $18 \mathrm{~h}$. This solution was then removed in vacuo and the cleaved peptoid resuspended in 200 $\mu \mathrm{L}$ of $80: 20 \mathrm{ACN}$ :water containing $0.05 \%$ TFA and analyzed by MS. The $\beta$-strand of the test peptoid was analyzed by treating a small aliquot of resin with $500 \mu \mathrm{L}$ of tris(2carboxyethyl)phosphine (TCEP; $1 \mathrm{mM}$ ) in water for $1 \mathrm{~h}$ at room temperature. The resulting supernatant was then analyzed by MS. The $\alpha$-strand of the peptoid was analyzed by washing the TCEP treated aliquot of resin $3 \mathrm{x}$ with water and subsequently treating with $75 \mu \mathrm{L} \mathrm{CNBr}$ (40 $\mathrm{mg} / \mathrm{mL}$ ) in 80:20 ACN:water containing $0.1 \mathrm{M} \mathrm{HCl}$ for $18 \mathrm{~h}$. This solution was then removed in vacuo and the cleaved peptoid resuspended in $200 \mu \mathrm{L}$ of 80:20 acetonitrile:water containing $0.05 \%$ TFA and analyzed by MS and MS/MS.

\section{Synthesis of PLAD Linked $\mathrm{C13}_{4 \mathrm{mer}}$}

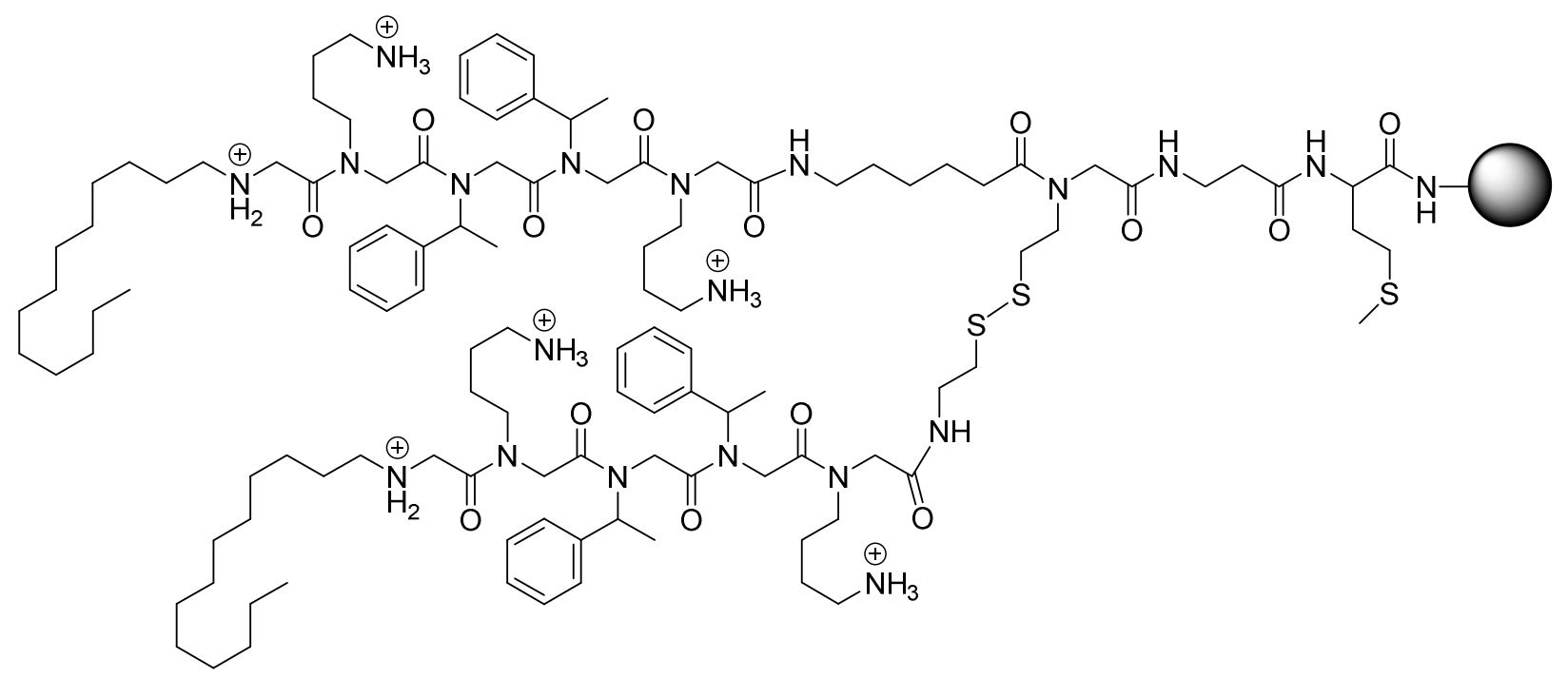

To $150 \mathrm{mg}$ of resin immobilized branched disulfide linker was added bromoacetic acid (0.414 g; $3 \mathrm{mmol})$ in anhydrous DMF $(1.5 \mathrm{~mL})$ and DIC $(0.75 \mathrm{~mL} ; 4.8 \mathrm{mmol})$ in anhydrous DMF $(1.5 \mathrm{~mL})$. This mixture was microwaved $2 \mathrm{x}$ at $10 \%$ power $(100 \mathrm{~kW})$ for 15 seconds, 
rocked gently for 15 minutes, and washed 4x with DMF. $N$-(tert-butoxycarbonyl)-1,4diaminobutane (300 mg, $1.59 \mathrm{mmol})$ in anhydrous DMF (3 mL) was then added, microwaved 2x at $10 \%$ power for 15 seconds, and reacted for 30 minutes, followed by washing $4 \mathrm{x}$ with DMF. The bromoacetic acid and DIC step was then repeated as described above. Phenylethylamine (2 $\mathrm{M})$ in anhydrous DMF (3 mL) was added, microwaved, and allowed to react for 30 minutes, after which it was washed with $4 \mathrm{x}$ with DMF. These procedures were then repeated with phenylethylamine and $N$-(tert-butoxycarbonyl)-1,4-diaminobutane again, respectively. After an additional bromoacetic acid/DIC coupling step, 1-aminotridecane (2 M) in anhydrous DMF (3 $\mathrm{mL}$ ) was added to the resin, microwaved, and rocked gently for 50 minutes. Resin was then washed $4 \mathrm{x}$ with $\mathrm{CH}_{2} \mathrm{Cl}_{2}$ and $4 \mathrm{x}$ with DMF. Deprotection of remaining Boc groups was then accomplished using $8 \mathrm{~mL}$ of a $95 \% \mathrm{TFA} / 2.5 \% \mathrm{H}_{2} \mathrm{O} / 2.5 \%$ TIS solution for $1 \mathrm{hr}$. Resin was then washed $5 \mathrm{x}$ with $\mathrm{CH}_{2} \mathrm{Cl}_{2}$ and $5 \mathrm{x}$ with DMF. All reactions were tested using a ninhydrin color test.

The complete $\mathrm{C} 13_{4 \mathrm{mer}}$ was analyzed by treating a small aliquot of resin with $75 \mu \mathrm{L}$ of cyanogen bromide $(\mathrm{CNBr} ; 40 \mathrm{mg} / \mathrm{mL})$ in 80:20 ACN:water containing $0.1 \mathrm{M} \mathrm{HCl}$ for $18 \mathrm{~h}$. This solution was then removed in vacuo and the cleaved peptoid resuspended in $200 \mu \mathrm{L}$ of 80:20 acetonitrile:water containing $0.05 \%$ TFA and analyzed by MS. The $\beta$-strand of the test peptoid was analyzed by treating a small aliquot of resin with $500 \mu \mathrm{L}$ of tris(2-carboxyethyl)phosphine (TCEP; $1 \mathrm{mM}$ ) in water for $1 \mathrm{~h}$ at room temperature. The resulting supernatant was then analyzed by MS. 


\section{Reducing Reagent Optimization}

Solid lysogeny broth (LB) was autoclaved at $121^{\circ} \mathrm{C}$ and agar plates $(10 \mathrm{~mL})$ were poured and kept at room temperature overnight to dry them of excess condensation. The solid agar was plated first to serve as a support to be overlaid with soft agar, allowing for a smooth, thin layer for the peptoid modified TentaGel resin to be dispersed in. Overnight culture was prepared in LB broth $(5 \mathrm{~mL})$ by inoculating with ATCC 25922 E. coli frozen stock and incubating at $37^{\circ} \mathrm{C}$ for $20 \mathrm{~h}$. TentaGel beads functionalized with PLAD linked $\mathrm{C} 13_{4 \text { mer }}$ were washed $2 \mathrm{x}$ with $\mathrm{H}_{2} \mathrm{O}$ then allowed to equilibrate overnight in $\mathrm{H}_{2} \mathrm{O}$. Soft agar for overlay was heated to $100^{\circ} \mathrm{C}$ for 30 minutes and cooled to $47^{\circ} \mathrm{C}$, which kept it liquid. Compound beads were then equilibrated in $500 \mu \mathrm{L}$ phosphate-buffer saline (PBS; pH 7.2), for each plate, for 30 minutes. Soft agar (3 mL), $75 \mu \mathrm{L}$ of E. coli overnight culture, and PLAD linked $\mathrm{C} 13_{4 \text { mer }}$ beads in PBS solution $(500 \mu \mathrm{L})$ were then combined, and inverted 6-7 times gently to avoid air bubbles. This mixture, serving as the negative control with no reducing reagent, was then poured onto a hard agar plate and spread evenly into a thin layer by manual agitation. Dithiothreitol (DTT), 2-mercaptoethanol (BME), and tris(2-carboxyethyl)phosphine (TCEP) were then tested at varying concentrations to determine effectiveness at releasing the peptoid $\beta$-strand from the bead while maintaining good bacterial growth. Stock solutions of $100 \mathrm{mmol} / \mathrm{L}$ DTT, BME, and TCEP were prepared in PBS $(\mathrm{pH}$ 7.2). Each reducing agent was tested as described above by addition of the appropriate amount of stock reagent to separate individual plates. Final concentrations of reducing reagent in the soft agar overlay mixture $2,4,10$, and $14 \mathrm{mmol} / \mathrm{L}$ for all three reducing agent. All plates were then allowed to solidify and incubated at $37^{\circ} \mathrm{C}$ for 18 hours. Zones of inhibition, defined as the distance between the edge of a bead and the beginning of bacterial growth near that bead, were measured using a Leica M165FC microscope. Images were also analyzed by Adobe 
Photoshop to gain a measure of bacterial lawn density by measuring the light reflected off of the bacterial lawn when illuminated at an angle. Both sets of analyses, zone of inhibition measurements and bacterial lawn density measurements were performed on the same plates; bacterial lawn density was measured in areas of the plate where beads were not found.

\section{Proof-of-Concept Library Synthesis}

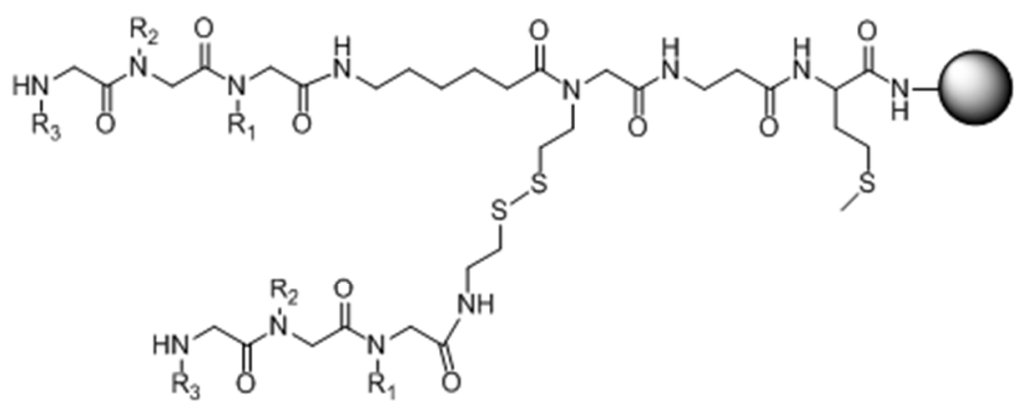

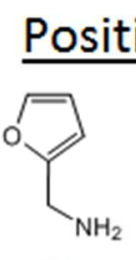

A

\section{Position 2}

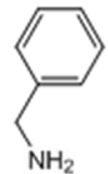

$\mathrm{B}$

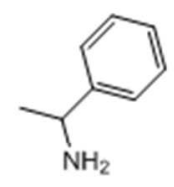

$\mathrm{C}$

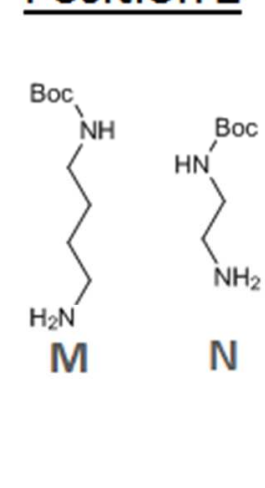

N

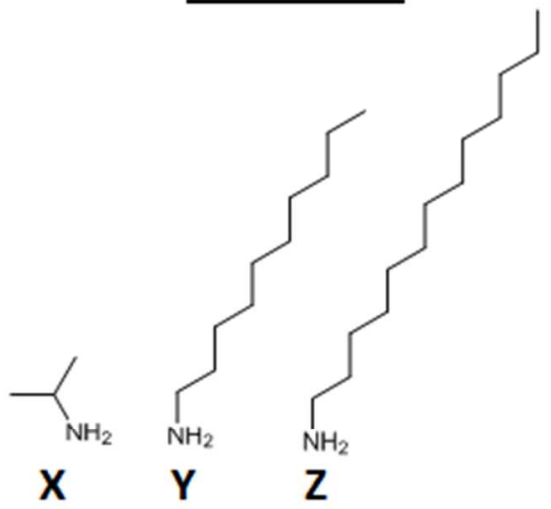

To $100 \mathrm{mg}$ of resin modified with branched disulfide linker was equilibrated in anhydrous DMF and bromoacetic acid $(0.414 \mathrm{~g} ; 3 \mathrm{mmol})$ in anhydrous DMF $(1.5 \mathrm{~mL})$ and DIC $(0.75 \mathrm{~mL} ; 4.8 \mathrm{mmol})$ in anhydrous DMF $(1.5 \mathrm{~mL})$ were added. This mixture was microwaved $2 \mathrm{x}$ at $10 \%$ power $(100 \mathrm{~kW})$ for 15 seconds, rocked gently for 30 minutes, and washed $4 \mathrm{x}$ with DMF. Anhydrous DMF $(3 \mathrm{~mL})$ was then added and the resin was split into three vials $(1 \mathrm{~mL}$ 
each). DMF was removed from each vial and to the first was added $2 \mathrm{M}$ furfurylamine in anhydrous DMF (2 mL), to the second $2 \mathrm{M}$ benzylamine in anhydrous DMF (2 $\mathrm{mL})$, and to the third $2 \mathrm{M}$ phenylethylamine in anhydrous DMF $(2 \mathrm{~mL})$. All three vials were then microwaved $2 \mathrm{x}$ at $10 \%$ power $(100 \mathrm{~kW})$ for 15 seconds and rocked gently for 30 minutes. The resin from the three vials was then pooled together and washed $4 \mathrm{x}$ with DMF and equilibrated in anhydrous DMF. Bromoacetic/DIC coupling was then done for 30 minutes and the resin was washed $4 x$ with DMF. Anhydrous DMF (2 mL) was added, and the resin was split into two vials $(1 \mathrm{~mL}$ each). DMF was removed from both vials and to the first vial $N$-(tert-butoxycarbonyl)-1,4diaminobutane $(700 \mathrm{mg}, 1.85 \mathrm{M})$ in anhydrous DMF $(2 \mathrm{~mL})$ was added, and to the second vial $N$-(tert-butoxycarbonyl)-1,2-diaminoethane $(550 \mathrm{mg}, 1.80 \mathrm{M})$ in anhydrous DMF $(2 \mathrm{~mL})$ was added. Both vials were microwaved $2 \mathrm{x}$ at $10 \%$ power $(100 \mathrm{~kW})$ for 15 seconds and rocked gently for 30 minutes. The two vials were combined and washed $4 \mathrm{x}$ with DMF, then equilibrated in anhydrous DMF. Bromoacetic/DIC coupling was then done for 30 minutes and the resin was washed with DMF 4x. Anhydrous DMF ( $3 \mathrm{~mL})$ was then added to the resin and split into three separate vials. The DMF was removed and to the first vial $2 \mathrm{M}$ isopropylamine in anhydrous DMF (2 mL) was added, to the second vial 2 M 1-aminodecane in anhydrous DMF (2 $\mathrm{mL}$ ) was added, and to the third vial $2 \mathrm{M} 1$-aminotridecane in anhydrous DMF (2 mL) was added. These amine coupling vials were microwaved $2 \mathrm{x}$ at $10 \%$ power $(100 \mathrm{~kW})$ for 15 seconds and rocked gently for 30 minutes. Vials were then pooled and washed $4 \mathrm{x}$ with DMF and $4 \mathrm{x}$ with $\mathrm{CH}_{2} \mathrm{Cl}_{2}$. Deprotection of Boc groups was accomplished using $8 \mathrm{~mL} 95 \% \mathrm{TFA} / 2.5 \% \mathrm{H}_{2} \mathrm{O} / 2.5 \%$ TIS solution for 1 hour. Resin was washed $5 \mathrm{x}$ with $\mathrm{CH}_{2} \mathrm{Cl}_{2}$ followed by $5 \mathrm{x}$ with DMF. This semi-combinatorial synthesis resulted in 18 unique peptoid sequences immobilized on the PLAD 
linker system for proof-of-concept testing. Ninhydrin tests were done following each successive bromoacetic acid step and pooling of amines to show confirm successful coupling.

\section{Proof-of-Concept Library Screening}

Solid lysogeny broth (LB) was autoclaved at $121^{\circ} \mathrm{C}$ and agar plates $(10 \mathrm{~mL})$ were poured and kept at room temperature overnight to dry them of excess condensation. The solid agar was plated first to serve as a support to be overlaid with soft agar, allowing for a smooth, thin layer for the peptoid modified TentaGel resin to be dispersed in. Overnight culture was prepared in LB broth $(5 \mathrm{~mL})$ by inoculating with ATCC 25922 E. coli frozen stock and incubating at $37^{\circ} \mathrm{C}$ for $20 \mathrm{~h}$. Three aliquots of resin $(4 \mathrm{mg})$ functionalized with PLAD linked proof-of-concept library were washed $2 x$ with $\mathrm{H}_{2} \mathrm{O}$ then allowed to equilibrate overnight in $\mathrm{H}_{2} \mathrm{O}$. Soft agar for overlay was heated to $100^{\circ} \mathrm{C}$ for 30 minutes and cooled to $47^{\circ} \mathrm{C}$, which kept it liquid. The resin aliquots were then equilibrated in $500 \mu \mathrm{L}$ phosphate-buffer saline (PBS; $\mathrm{pH}$ 7.2) for 30 minutes. Soft agar $(3 \mathrm{~mL}), 75 \mu \mathrm{L}$ of E. coli overnight culture, $500 \mu \mathrm{L}$ of TCEP (100 mM stock; $14 \mathrm{mM}$ final) and resin in PBS (500 $\mu \mathrm{L})$ were then combined, and inverted 6-7 times gently to avoid air bubbles. This mixture was then poured onto a hard agar plate and spread evenly into a thin layer by manual agitation. All plates were then allowed to solidify and incubated at $37^{\circ} \mathrm{C}$ for 18 hours. Zones of inhibition, defined as the distance between the edge of a bead and the beginning of bacterial growth near that bead, were measured using a Leica M165FC microscope. Hits, defined as beads with a measurable zone of inhibition, were isolated manually with surgical tweezers and placed into individual tubes. These beads were boiled in $1 \%$ sodium dodecylsulfate (SDS) for 1 hour and washed $4 \mathrm{x}$ with water. The alpha strand of the peptoid was cleaved from the bead using cyanogen bromide $(50 \mu \mathrm{L} ; 40 \mathrm{mg} / \mathrm{mL})$ in $80: 20$ acetonitrile:water 
containing $0.1 \mathrm{M} \mathrm{HCl}$ for 18 hours in the dark. This solution was then removed in vacuo and the cleaved peptoid resuspended in 80:20 acetonitrile:water containing 0.05\% TFA. MS and MS/MS analysis was then done as previously described to identify the structure of the unknown peptoid. In total 34 hits were identified ( $24 \%$ hit rate) and 31 sequences were successfully obtained by MS and MS/MS.

\section{Synthesis of K15 Peptoid}

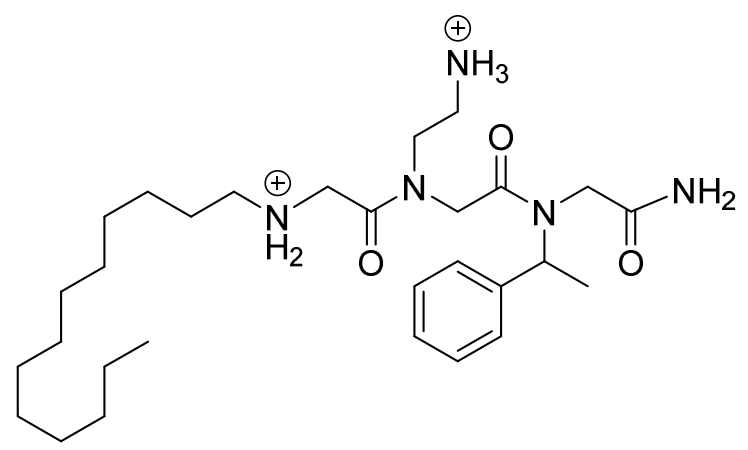

Rink Amide resin $(0.101 \mathrm{~g} ; 0.38 \mathrm{mmol} / \mathrm{g}$ loading) was swollen in DMF for 20 minutes. After removing the DMF, $20 \%$ piperidine in DMF $(5 \mathrm{~mL})$ was added to the resin and rocked for 30 minutes. The piperidine solution was drained, and the beads were washed $3 \mathrm{x}$ with DMF. The piperidine deprotection step was once more repeated, and the resin washed $3 \mathrm{x}$ with DMF. Solutions of bromoacetic acid $(0.417 \mathrm{~g} ; 3 \mathrm{mmol})$ in anhydrous DMF $(1.5 \mathrm{~mL})$ and DIC (0.75 $\mathrm{mL} ; 4.8 \mathrm{mmol})$ in anhydrous DMF $(1.5 \mathrm{~mL})$ were combined with the deprotected Rink Amide beads. The resin was microwaved twice at $10 \%$ power $(100 \mathrm{~kW})$ for 15 seconds, then rocked gently for 15 minutes; after which, the mixture was aspirated and washed four times with DMF. 2-phenylethylamine $(0.364 \mathrm{~g} ; 3 \mathrm{mmol})$ in anhydrous DMF $(3.0 \mathrm{~mL})$ was added to the resin and microwaved twice at $10 \%$ power for 15 seconds followed by gentle rocking for 30 minutes. The 
suspension was aspirated and washed 4x with DMF. The previously descried bromoacetic acid and DIC reaction was repeated. Boc-ethylene diamine $(0.486 \mathrm{~g} ; 3 \mathrm{mmol})$ in anhydrous DMF (3.0 mL) was added, microwaved, and rocked for 30 minutes. The suspension was then aspirated and washed $4 \mathrm{x}$ with DMF. Again, the bromoacetic acid and DIC coupling was repeated. Tridecylamine $(0.598 \mathrm{~g} ; 3 \mathrm{mmol})$ in anhydrous DMF $(3.0 \mathrm{~mL})$ was added to the resin, microwaved, and rocked for 40 minutes. The mixture was aspirated and washed 4x with DMF and $4 \mathrm{x}$ with $\mathrm{CH}_{2} \mathrm{Cl}_{2}$. A ninhydrin test was performed on a small sample after every coupling. The tripeptoid was cleaved from the resin by treating $2 \mathrm{x}$ with TFA:water:TIS $(95: 2.5: 2.5)$ for $1 \mathrm{~h}$ each. TFA was removed by bubbling with air and residual substance resuspended in 1:1 water:acetonitrile containing $0.05 \%$ TFA. K15 was then purified by reverse phase HPLC using a C18 column and a gradient of water with $0.05 \%$ TFA to acetonitrile with $0.05 \%$ TFA. The identity of the compound was confirmed by MS and the solvent removed under vacuum to provide pure K15 (17 mg; 17\% yield).

\section{K15 MIC Testing in ESKAPE Pathogens}

Peptoid K15 was analyzed via a traditional broth minimum inhibitor concentration (MIC) assay against seven different ESKAPE pathogens (Acinetobacter baumanii, ATCC 19606; Enterococcus faecalis, ATCC 29212; Enterococcus faecium, ATCC 19434; Escherichia coli, ATCC 25922; Klebsiella pneumoniae, ATCC 700603; Pseudomonas aeruginosa, ATCC 27853; Staphylococcus aureus, ATCC 29213). For each of the bacterial strains screened in the ESKAPE panel, 1-3 isolated colonies were collected from a TSA plate by a flame sanitized wire loop and resuspended in $5 \mathrm{~mL}$ of TSB. The solutions were incubated at $37^{\circ} \mathrm{C}$ for $18-24$ hours. After the growth period, the turbidity was measured at $600 \mathrm{~nm}$ and adjusted to an optical density 
of $0.08-0.13$ by diluting with TSB for an approximate concentration of $1 \times 10^{8} \mathrm{CFU} / \mathrm{mL}$. Once the desired OD was achieved, $20 \mu \mathrm{L}$ of the bacteria suspension were diluted 1:20 in $380 \mu \mathrm{L}$ Cation Adjusted Mueller-Hinton broth (CAMHB) for a final concentration of $5 \times 10^{6} \mathrm{CFU} / \mathrm{mL}$.

$4 \mu \mathrm{L}$ of a $10 \mathrm{mM}$ stock of $\mathrm{K} 15$ were diluted in $356 \mu \mathrm{L}$ CAMHB for each bacterial strain assayed (a total of $28 \mu \mathrm{L}$ stock in $2.478 \mathrm{~mL}$ broth for ESKAPE panel). $180 \mu \mathrm{L}$ of this solution were delivered to three wells. For each dilution to be studied, $90 \mu \mathrm{L}$ of the $100 \mu \mathrm{M}$ solution were withdrawn and delivered to $90 \mu \mathrm{L}$ of broth This 1:2 serial dilution was continued to give final K15 concentrations of $100,50,25,12.5,6.3,3.1$, and $1.6 \mu \mathrm{M} .90 \mu \mathrm{L}$ of the final triplicate set being removed such that each well has a volume of $90 \mu \mathrm{L}$. A negative control containing $90 \mu \mathrm{L}$ of broth with no K15 was also prepared. $10 \mu \mathrm{L}$ of the 1:20 diluted bacteria were added to each well for a total volume of $100 \mu \mathrm{L} .100 \mu \mathrm{L}$ of broth were delivered to a well in triplicate to serve as a media control. A tetracycline control was used, composed of $4 \mu \mathrm{L} 2 \mathrm{mg} / \mathrm{mL}$ antibiotic in 356 $\mu \mathrm{L}$ broth with $40 \mu \mathrm{L}$ bacteria. $100 \mu \mathrm{L}$ of this solution were delivered to each of three wells.

The prepared plates were incubated for another 18-24 hours. Their respective absorbance at $600 \mathrm{~nm}$ was analyzed on a SpectraMax M5 Plate Reader. $10 \mu \mathrm{L}$ of PrestoBlue were added to each well and allowed to incubate for an hour. Absorbance at 555, 570, and $585 \mathrm{~nm}$ was analyzed to determine viable cells having survived treatment by the antimicrobial compound. This assay, which utilizes triplicates of each K15 concentration, was ran in duplicate or triplicate for each microorganism tested on different days. 


\section{Supporting Figures}

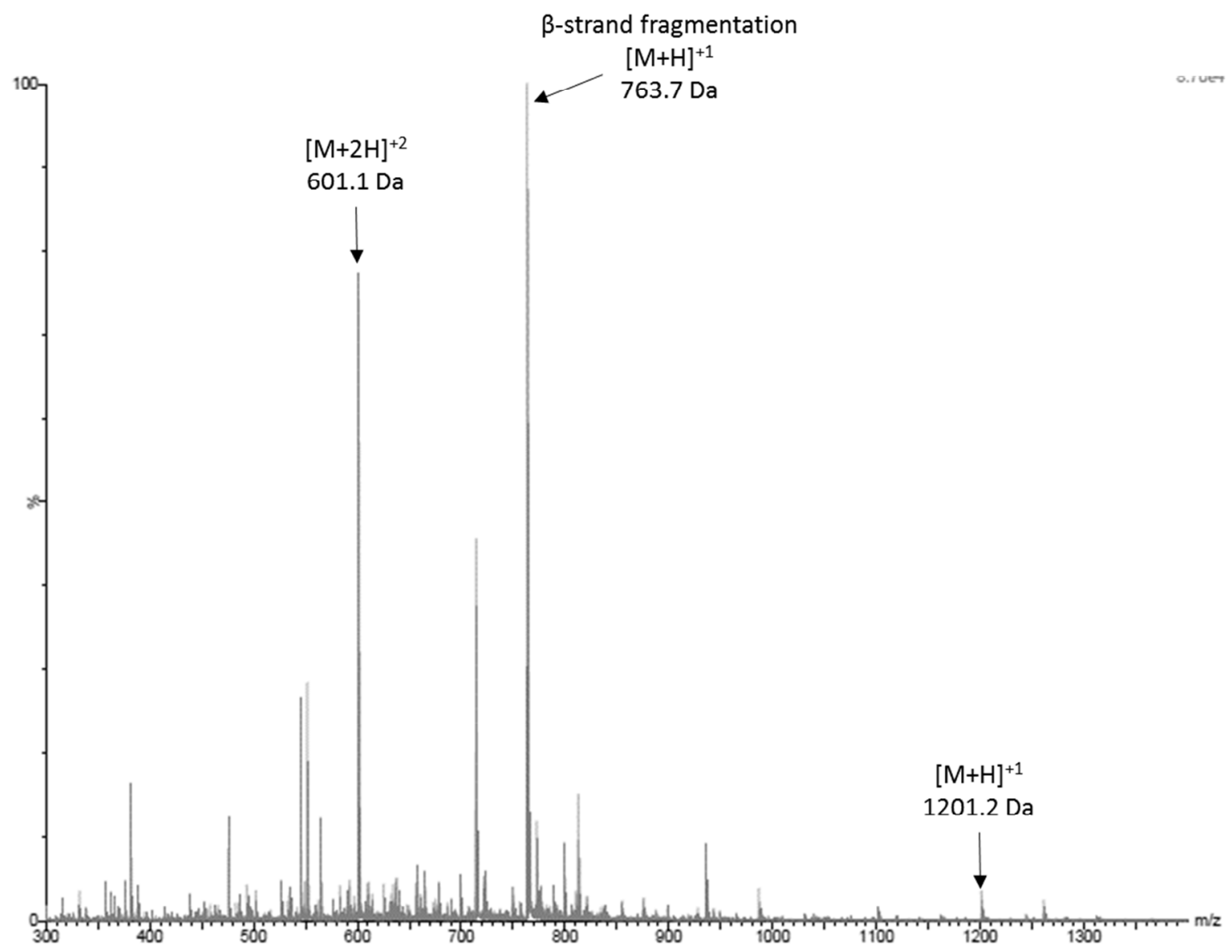

Figure S1. Linear MS of complete test peptoid, showing the desired compound at 1201.2 Da $(\mathrm{M}+\mathrm{H})$ and $601.1 \mathrm{Da}(\mathrm{M}+2 \mathrm{H})$. The disulfide bond is easily fragmented during $\mathrm{MS}$ analysis, giving the complete compound minus the $\beta$-strand at $763.7 \mathrm{Da}(\mathrm{M}+\mathrm{H})$. 


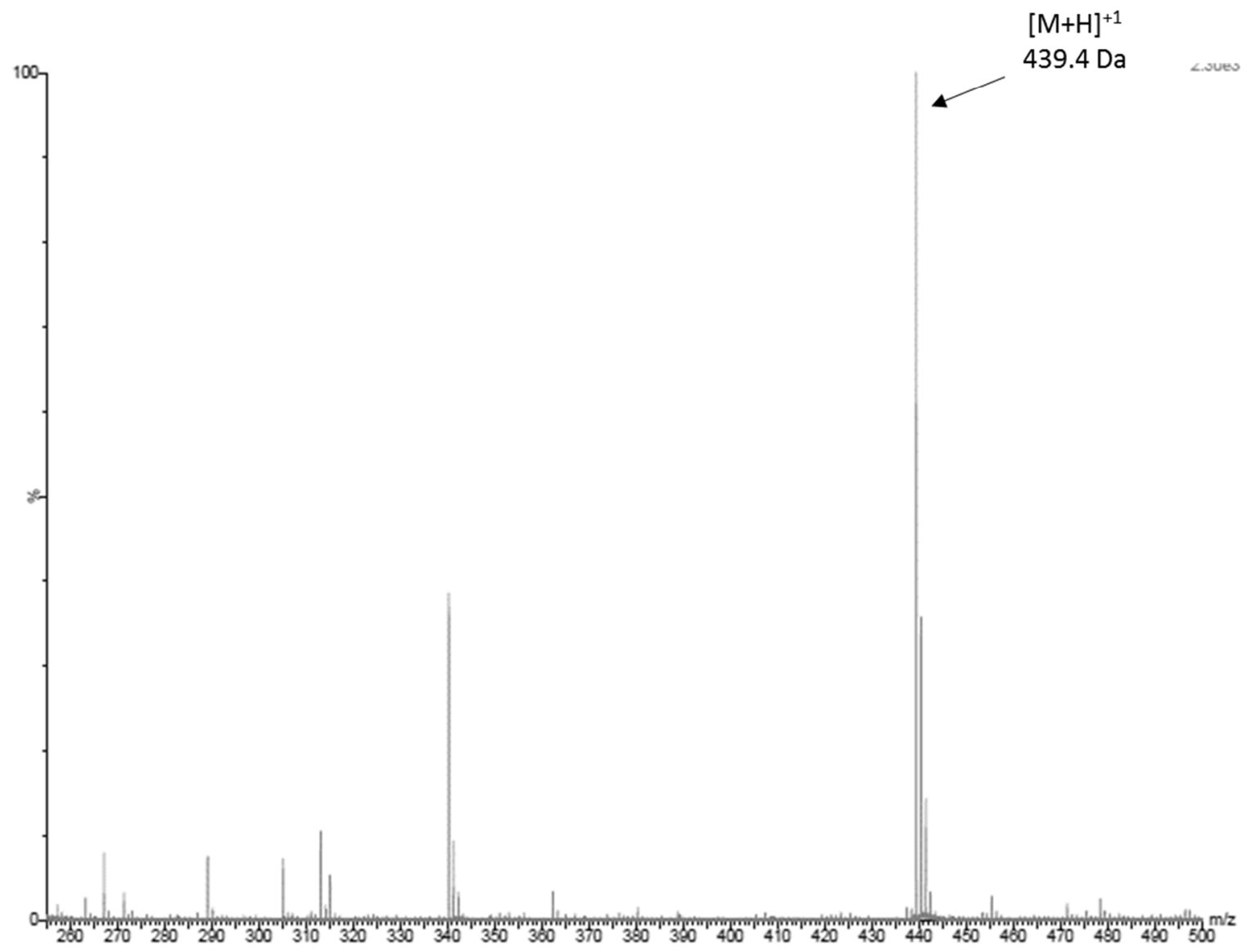

Figure S2. Linear MS of the $\beta$-strand of the test peptoid at 439.4 Da $(\mathrm{M}+\mathrm{H})$, released from the PLAD linker by treatment with TCEP. 


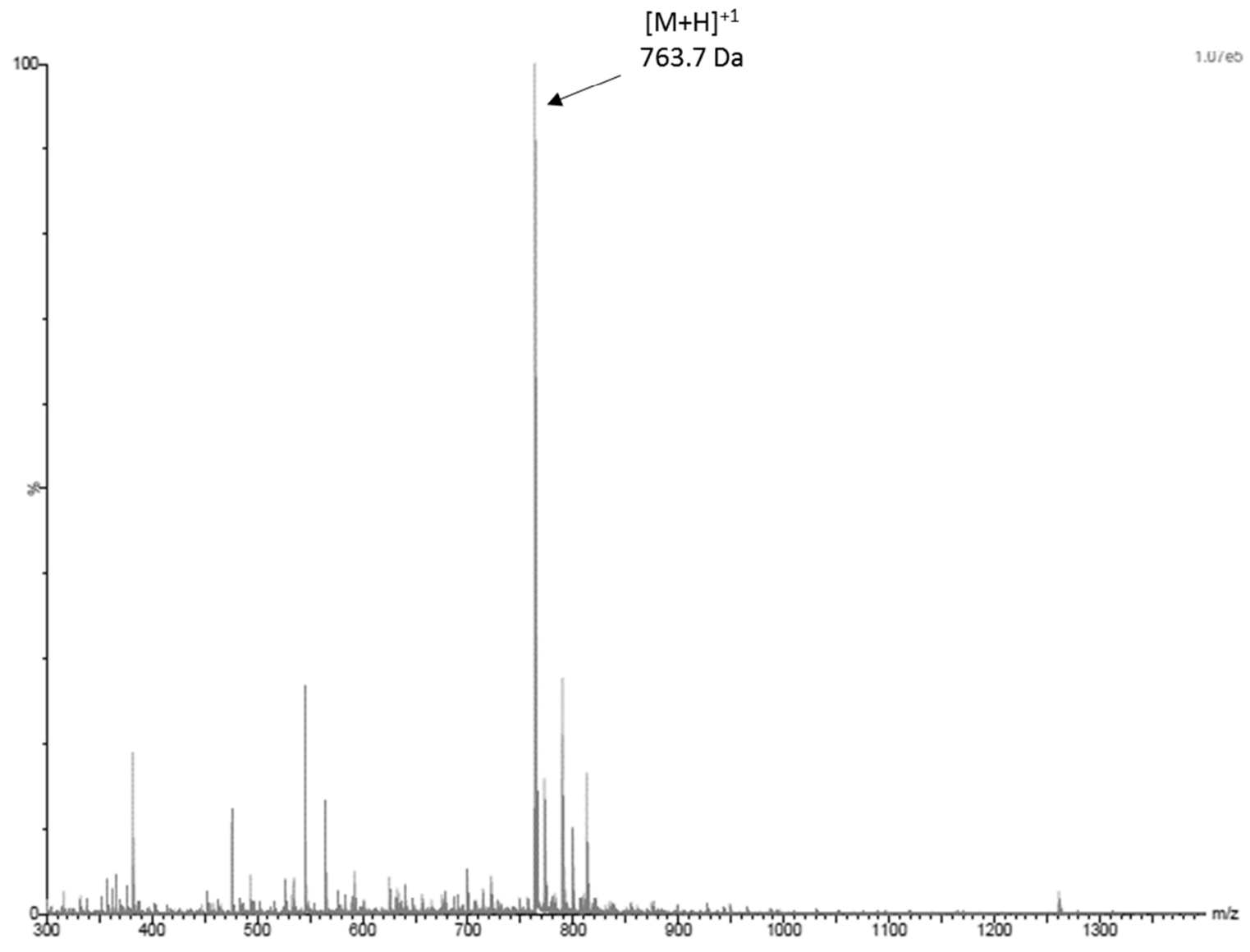

Figure S3. Linear MS of the $\alpha$-strand of the test peptoid at $763.7 \mathrm{Da}(\mathrm{M}+\mathrm{H})$ after $\beta$-strand cleavage by TCEP. 


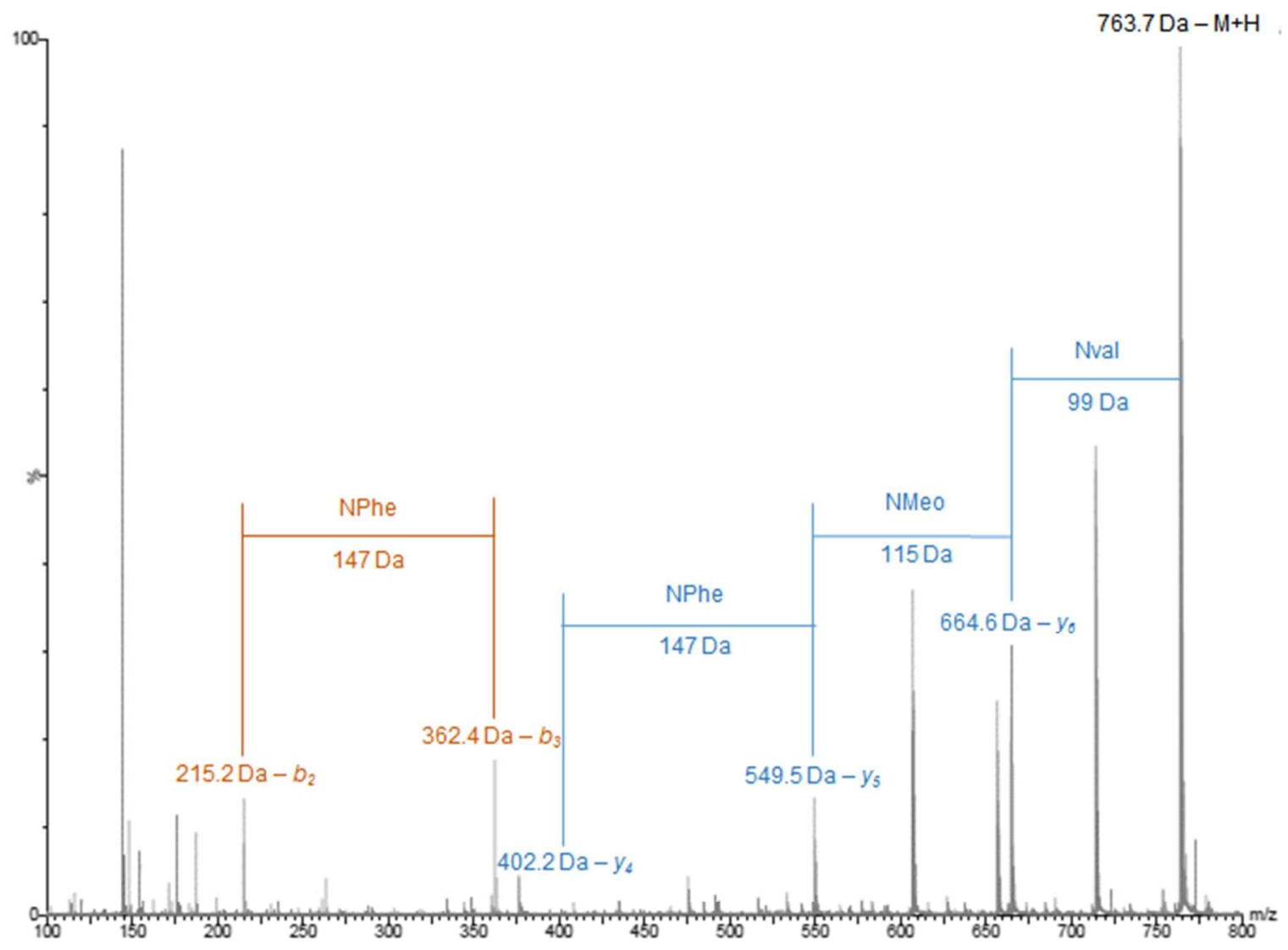

Figure S4. Tandem MS of the $\alpha$-strand of the test peptoid after $\beta$-strand cleavage by TCEP. The sequence of this compound (NVal-NMeo-NPhe-PLAD linker) can be confirmed using both $y$ ions (shown in blue) and $b$ ions (shown in orange). 


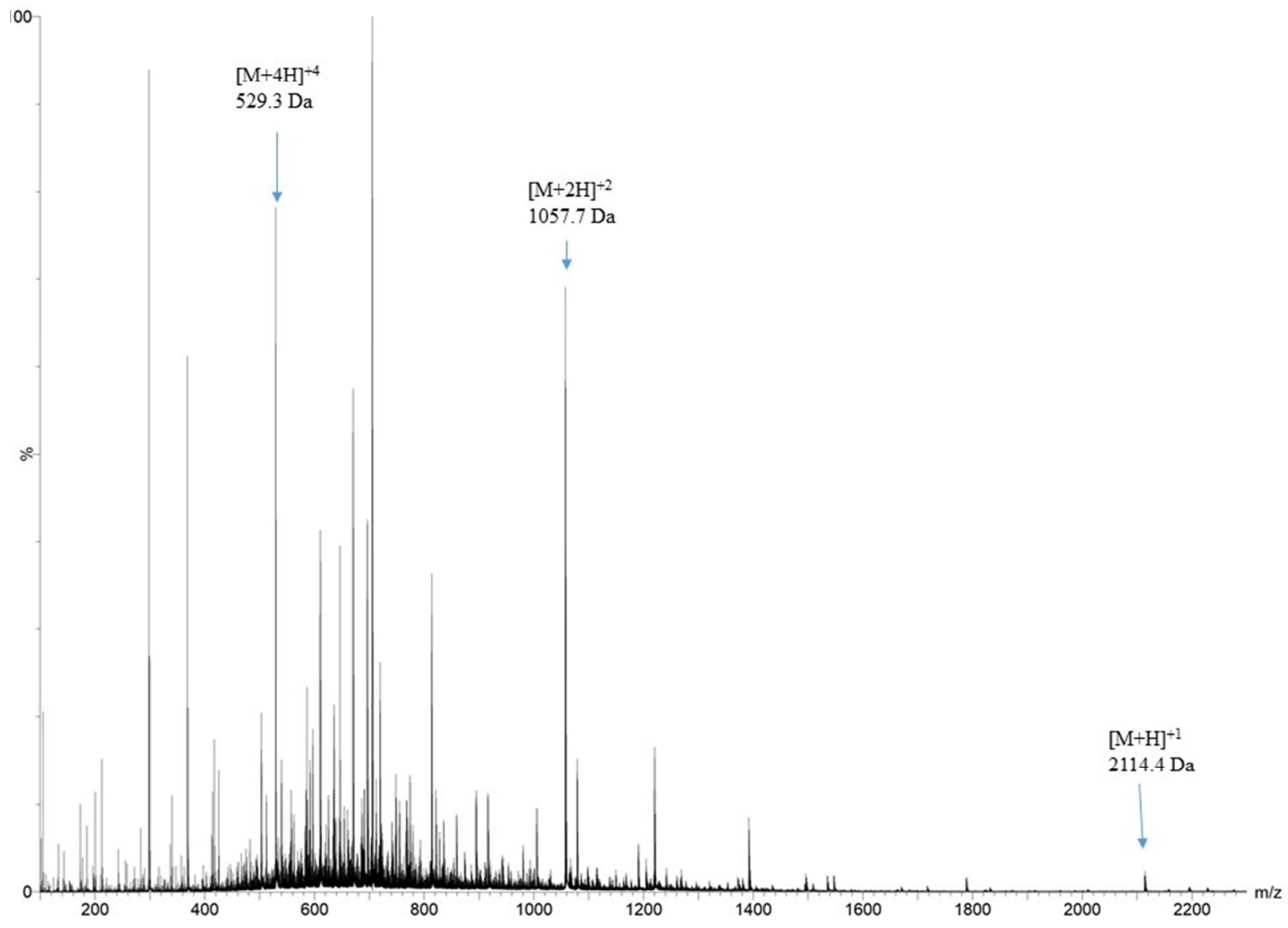

Figure S5. Linear MS of the complete C134mer, containing both the $\alpha$ and $\beta$-strands of the peptoid. 


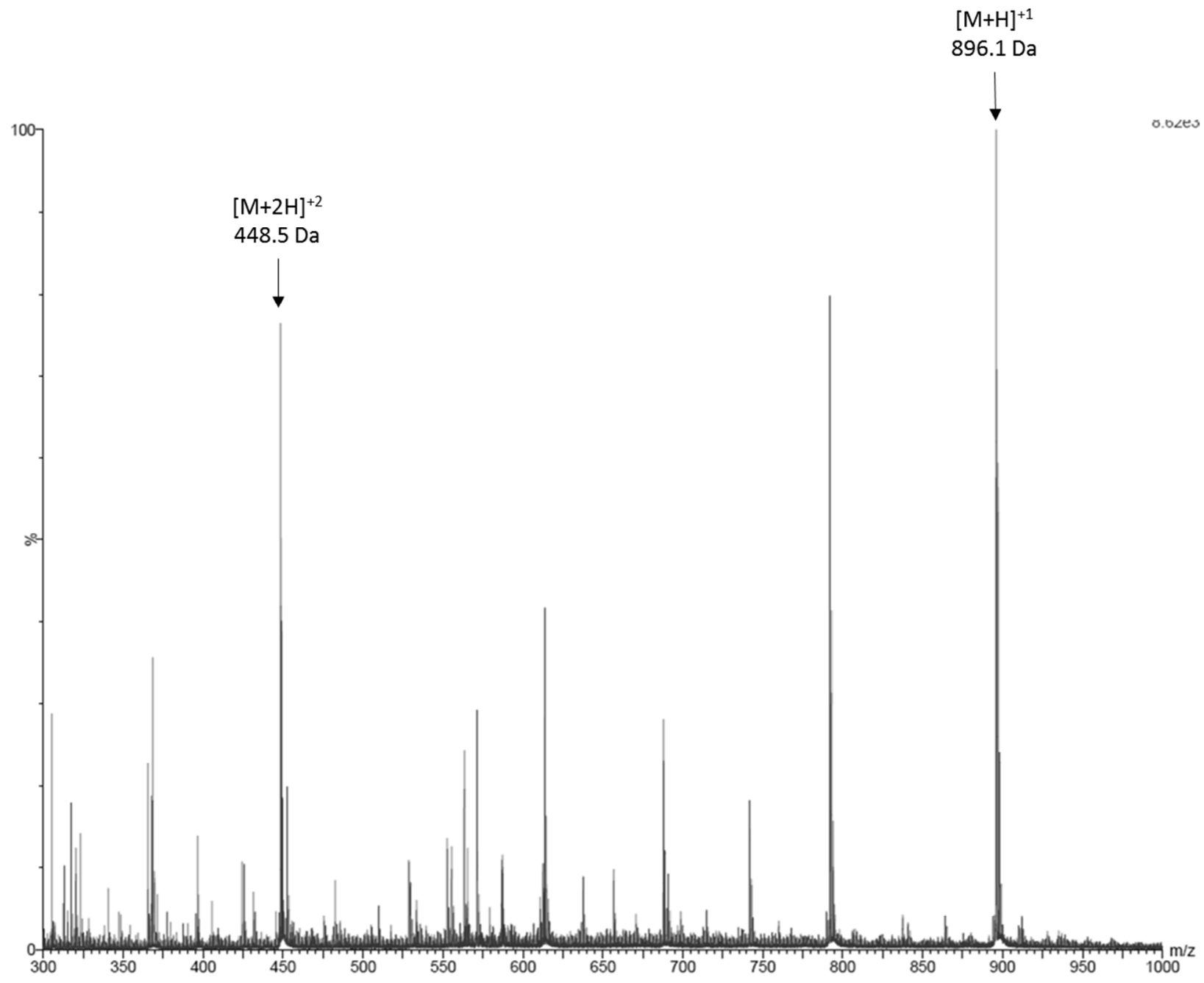

Figure S6. Linear MS of the $\beta$-strand of the PLAD linked $\mathrm{C} 13_{4 \mathrm{mer}}$, released using $1 \mathrm{mM}$ TCEP. 


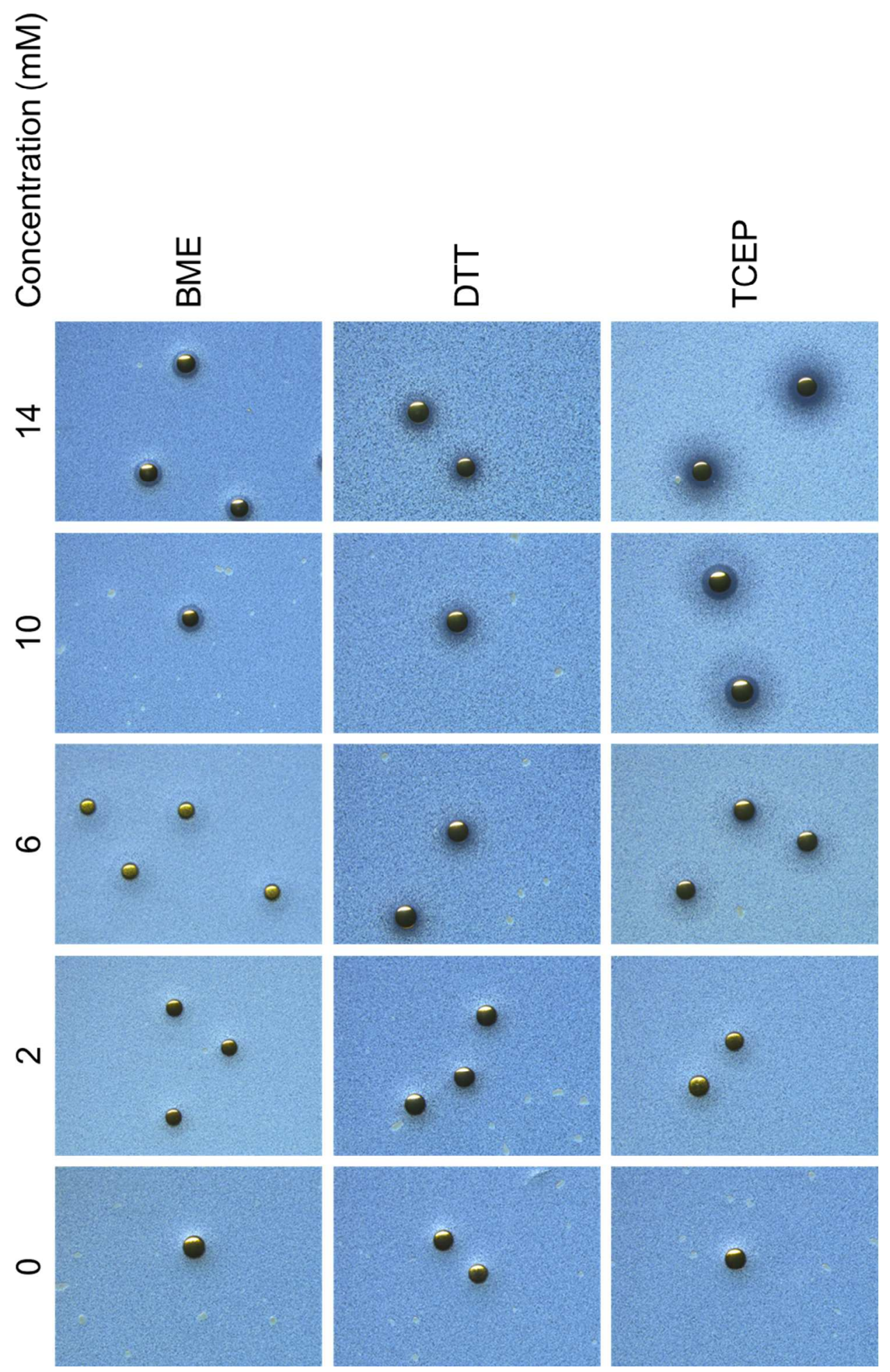

Figure S7. Cleaving reagent comparison and concentration optimization. Three different reducing reagents were tested at several different concentrations to determine the most suitable reducing reagent for screening. $\beta$-mercaptoethanol (BME); dithiothreitol (DTT); tris(2carboxyethyl)phosphine (TCEP) 


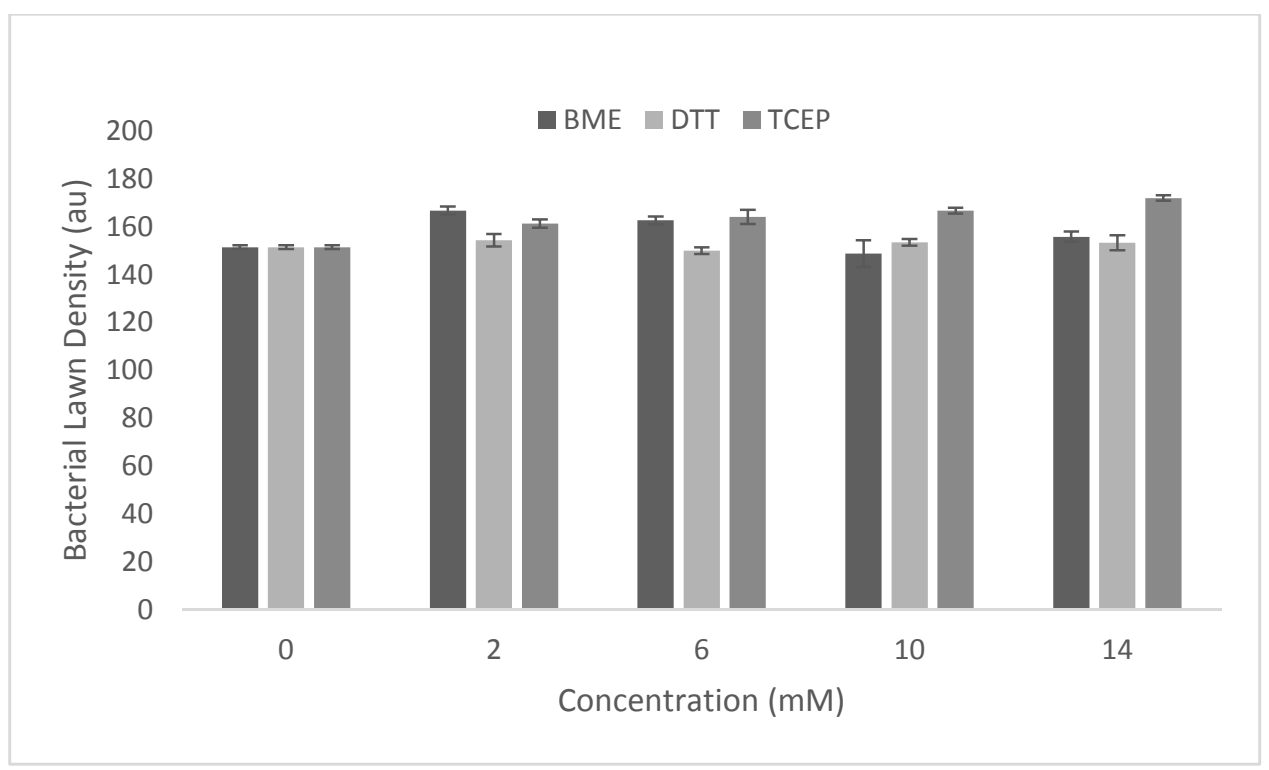

Figure S8. Cleaving reagent effect on bacterial lawn density, showing no appreciable decrease in bacterial lawn density with increasing reducing reagent concentration. 


\begin{tabular}{|llccc|}
\hline & $\mathbf{C}$ & Position & \multicolumn{2}{c|}{ N } \\
\hline Sequence & $\mathbf{1}$ & $\mathbf{2}$ & $\mathbf{3}$ & MS MW (Da) \\
\hline KJF1 & NFur & Nae & NVal & 739 \\
\hline KJF2 & NFur & Nae & NDec & 837 \\
\hline KJF3 & NFur & Nae & NTri & 879 \\
\hline KJF4 & NFur & NLys & NVal & 767 \\
\hline KJF5 & NFur & NLys & NDec & 865 \\
\hline KJF6 & NFur & NLys & NTri & 907 \\
\hline KJF7 & NPhe & Nae & NVal & 749 \\
\hline KJF8 & NPhe & Nae & NDec & 847 \\
\hline KJF9 & NPhe & Nae & NTri & 889 \\
\hline KJF10 & NPhe & NLys & NVal & 777 \\
\hline KJF11 & NPhe & NLys & NDec & 875 \\
\hline KJF12 & NPhe & NLys & NTri & 917 \\
\hline KJF13 & NPea & Nae & NVal & 763 \\
\hline KJF14 & NPea & Nae & NDec & 861 \\
\hline KJF15 & NPea & Nae & NTri & 903 \\
\hline KJF16 & NPea & NLys & NVal & 791 \\
\hline KJF17 & NPea & NLys & NDec & 889 \\
\hline KJF18 & NPea & NLys & NTri & 931 \\
\hline
\end{tabular}

Figure S9. The identity, sequence, and molecular weight of each compound in the proof-ofconcept library. 

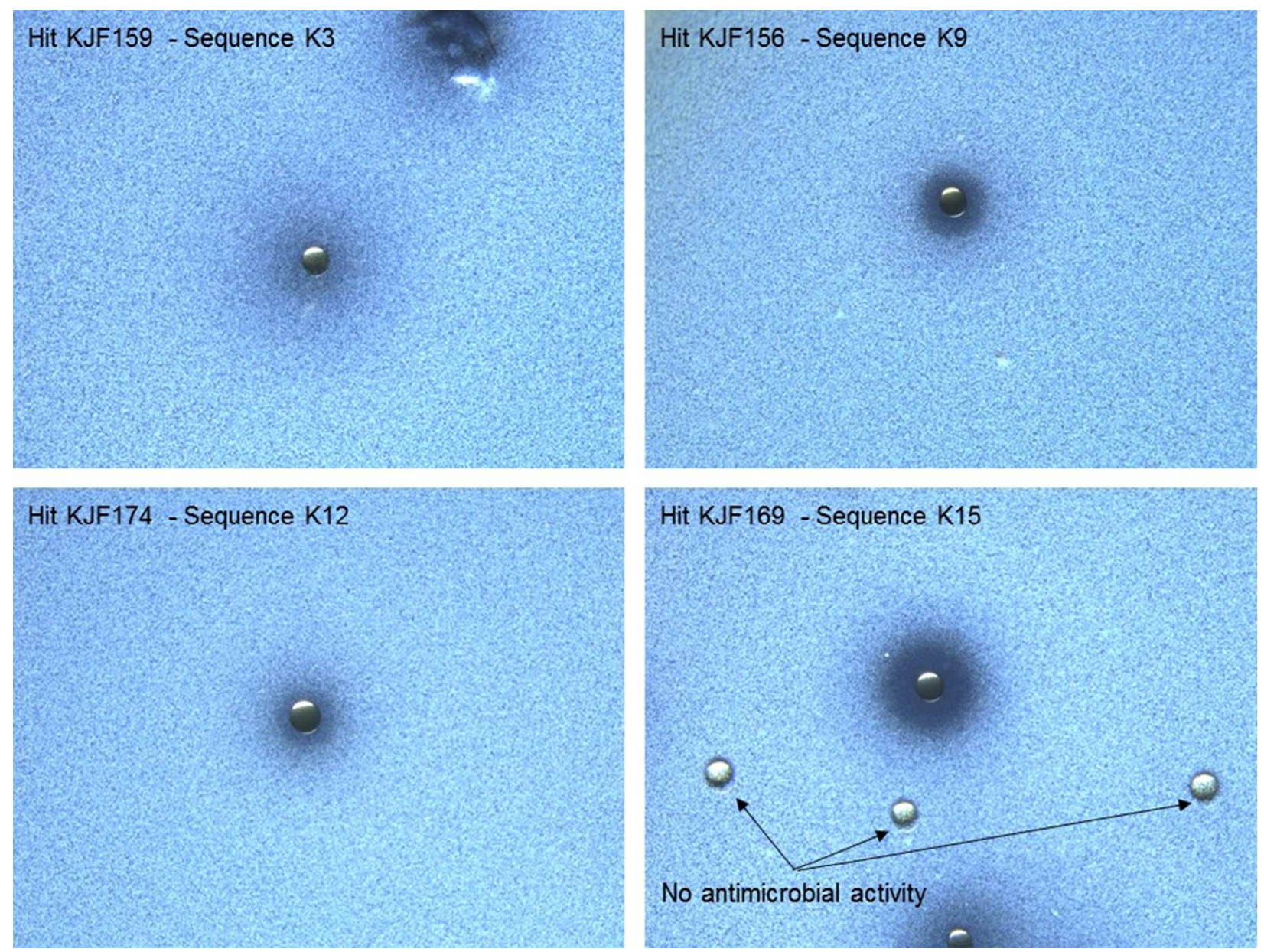

Figure S10. Representative images from screening of the PLAD linked proof-of-concept library. Easily visible zones of inhibition are observed around beads releasing peptoids with varying degrees of antimicrobial activity. Beads releasing peptoids from the library with no antimicrobial activity can be observed in the lower right image. 


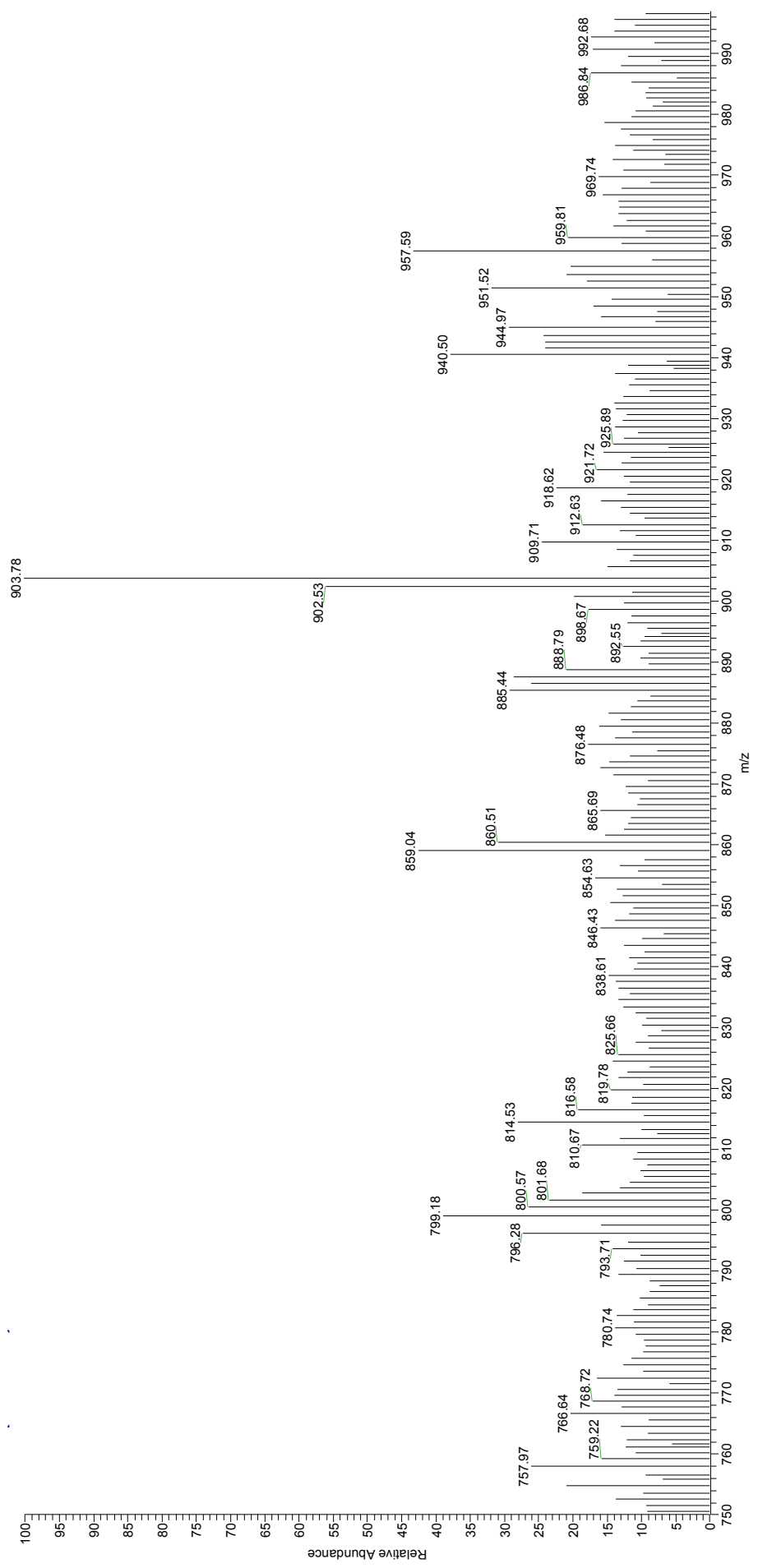

Figure S11. Linear MS of the $\alpha$-strand of a peptoid hit identified from the proof-of-concept library screening. With a molecular weight of 903 da, this hit was identified as sequence K15. 


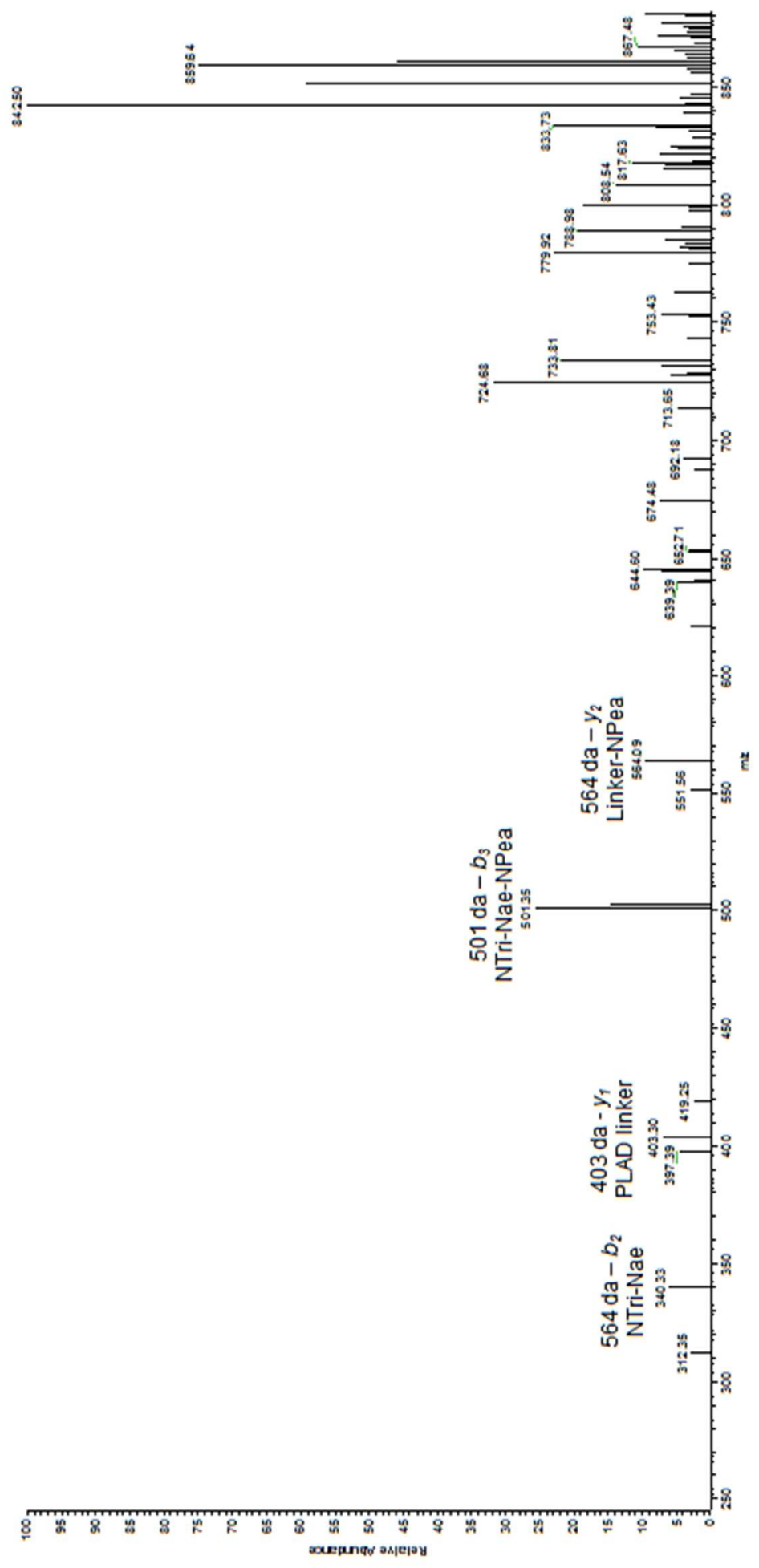

Figure S12. Tandem MS of the $\alpha$-strand of a peptoid hit identified as K15 during linear MS analysis. The $y$ and $b$ ions successfully identified are shown and confirm the sequence of this peptoid as K15. 


\begin{tabular}{|lccccc|}
\hline \multicolumn{5}{c}{ C } & \multicolumn{2}{c|}{ Position } \\
\hline Hit Identifier & MS MW (Da) & Sequence & $\mathbf{1}$ & $\mathbf{2}$ & $\mathbf{3}$ \\
\hline KJF150 & 931 & K18 & NPea & NLys & NTri \\
\hline KJF151 & 903 & K15 & NPea & Nae & NTri \\
\hline KJF154 & 917 & K12 & NPhe & NLys & NTri \\
\hline KJF155 & 931 & K18 & NPea & NLys & NTri \\
\hline KJF156 & 889 & K9 & NPhe & Nae & NTri \\
\hline KJF157 & 917 & K12 & NPhe & NLys & NTri \\
\hline KJF158 & 889 & K9 & NPhe & Nae & NTri \\
\hline KJF159 & 879 & K3 & NFur & Nae & NTri \\
\hline KJF160 & 931 & K18 & NPea & NLys & NTri \\
\hline KJF161 & 917 & K12 & NPhe & NLys & NTri \\
\hline KJF162 & 931 & K18 & NPea & NLys & NTri \\
\hline KJF163 & 889 & K9 & NPhe & Nae & NTri \\
\hline KJF164 & 903 & K15 & NPea & Nae & NTri \\
\hline KJF165 & 931 & K18 & NPea & NLys & NTri \\
\hline KJF166 & 903 & K15 & NPea & Nae & NTri \\
\hline KJF167 & 917 & K12 & NPhe & NLys & NTri \\
\hline KJF168 & 889 & K9 & NPhe & Nae & NTri \\
\hline KJF169 & 903 & K15 & NPea & Nae & NTri \\
\hline KJF170 & 917 & K12 & NPhe & NLys & NTri \\
\hline KJF171 & 879 & K3 & NFur & Nae & NTri \\
\hline KJF172 & 917 & K12 & NPhe & NLys & NTri \\
\hline KJF173 & 917 & K12 & NPhe & NLys & NTri \\
\hline KJF174 & 917 & K12 & NPhe & NLys & NTri \\
\hline KJF175 & 889 & K9 & NPhe & Nae & NTri \\
\hline KJF176 & 889 & K9 & NPhe & Nae & NTri \\
\hline KJF177 & 931 & K18 & NPea & NLys & NTri \\
\hline KJF178 & 889 & K9 & NPhe & Nae & NTri \\
\hline KJF179 & 903 & K15 & NPea & Nae & NTri \\
\hline KJF180 & 889 & K9 & NPhe & Nae & NTri \\
\hline KJF181 & 931 & K18 & NPea & NLys & NTri \\
\hline KJF183 & 931 & K18 & NPea & NLys & NTri \\
\hline
\end{tabular}

Figure S13. The identity and sequences of proof-of-concept peptoid library hits against E. coli ATCC 25922. 
A.<smiles>[R3]NCC(=O)N([R1])CC(=O)NCCSSCCN(CC(=O)NCCC(=O)NC(CCSC)C(=O)NCc1ccccc1)C(=O)CCCCCNC(=O)CN([R])C(=O)CN([R])C(=O)CN([R2])C(=O)CN[R3]</smiles>

B. Position 1

Position 2

Position 3<smiles>NCc1ccco1</smiles>

A

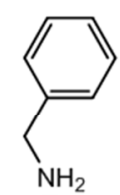

$\mathrm{B}$<smiles>CC(N)c1ccccc1</smiles>

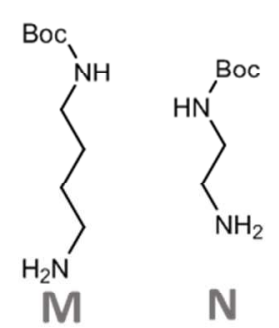

C

C.
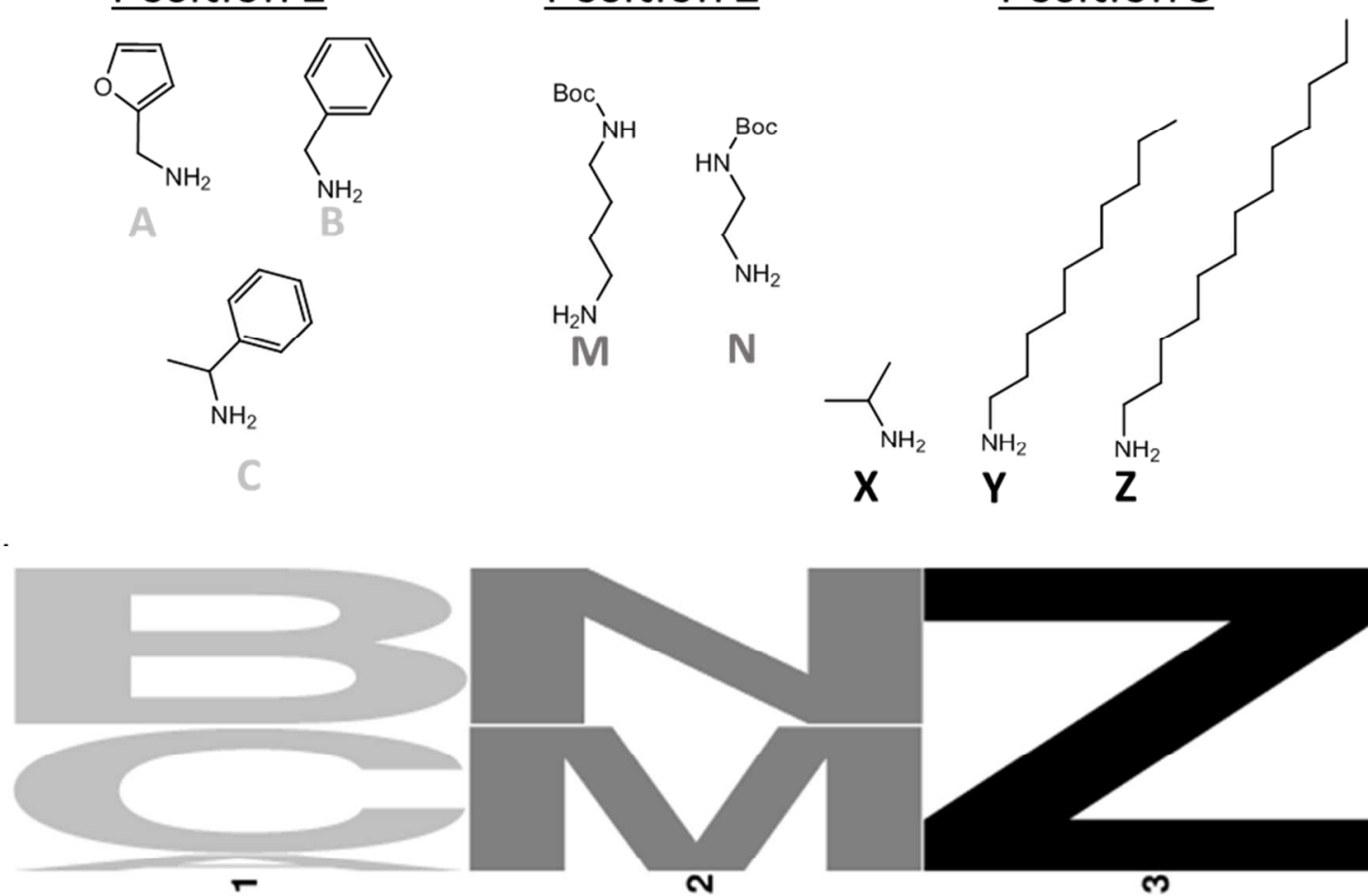

$\mathrm{X}$

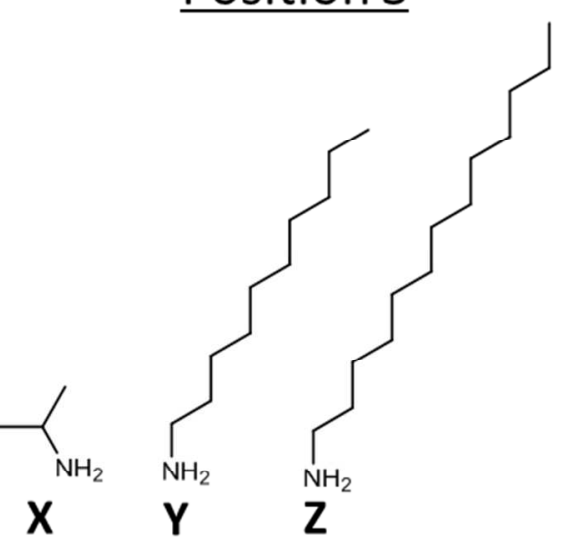

Figure S14. (A) General structure of the proof-of-concept PLAD linked library. (B) Amine submonomers incorporated into each of the positions in the library. (C) Homology chart from hits identified from screening of the proof-of-concept library indicating the prevalence of each submonomer at each position. 


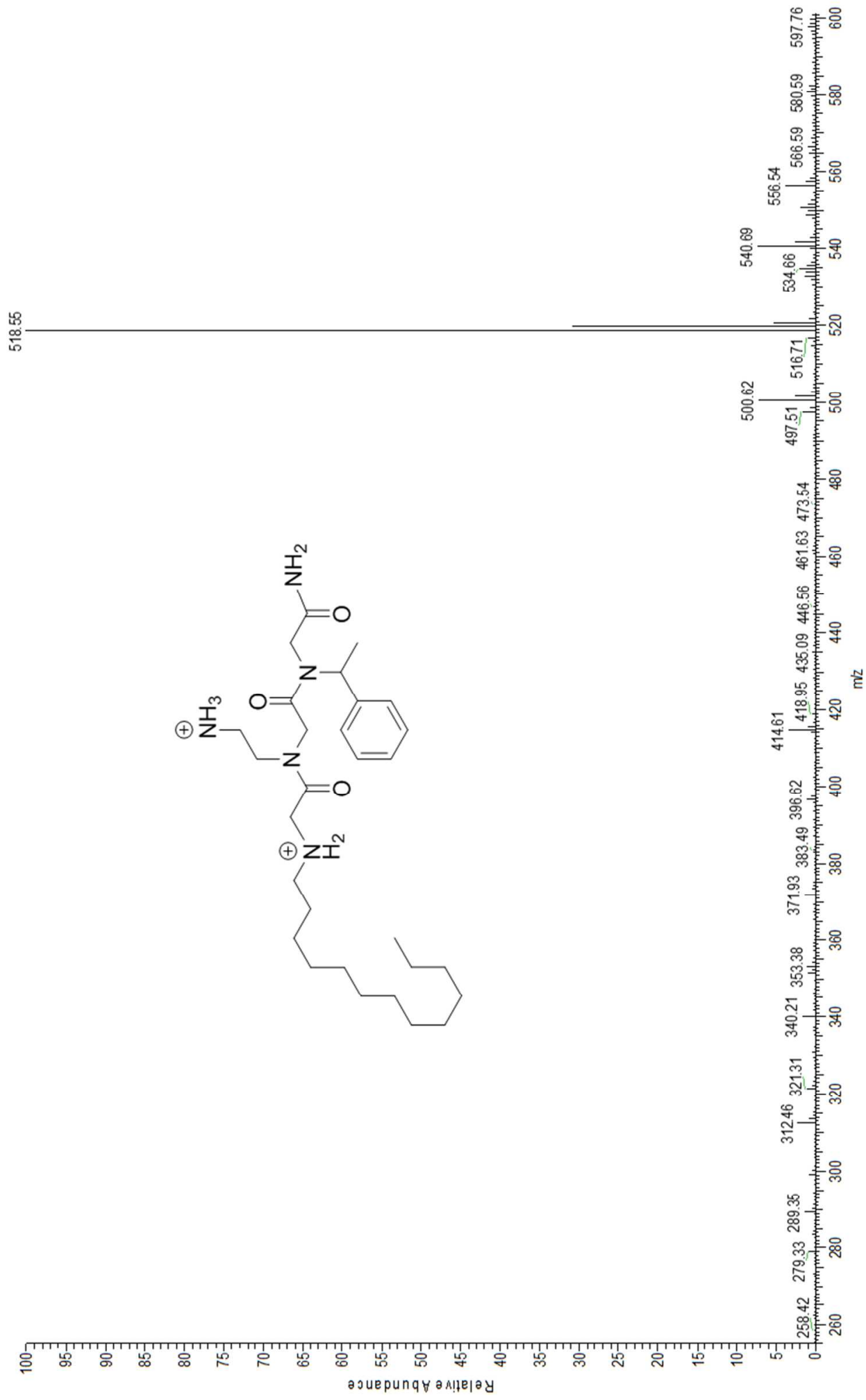

Figure S15. Structure and linear MS of K15 


\section{References}

1. Zuckermann, R. N.; Kerr, J. M.; Kent, S. B. H.; Moos, W. H., Efficient method for the preparation of peptoids [oligo(N-substituted glycines)] by submonomer solid-phase synthesis. Journal of the American Chemical Society 1992, 114, (26), 10646-10647. 